\title{
EFFICACY OF SUBLINGUAL MISOPROSTOL VERSUS OXYTOCIN DRIP FOR INDUCTION AND AUGMENTATION OF LABOUR IN PROM
}

Rekha Wadhwani, Deepti Gupta, Neelam Bangad

1. Associate Professor, Department of Obstetrics \& Gynaecology, Sultania Zanana Hospital, Gandhi Medical College, Bhopal

2. Assistant Professor, Department of Obstetrics \& Gynaecology, Sultania Zanana Hospital, Gandhi Medical College, Bhopal

3. Resident, Department of Obstetrics \& Gynaecology, Sultania Zanana Hospital, Gandhi Medical College, Bhopal .

\section{CORRESPONDING AUTHOR}

Dr Rekha Wadhwani,

IV/6, ESI Hospital campus, Sonagiri,

C- Sector, Raisen Road, BHEL, Bhopal,

Madhya Pradesh,

E-mail: drrekhaw@yahoo.co.in, deeptireja@gmail.com

Ph: 00919893019091,00919827267464

ABSTRACT: OBJECTIVES: To evaluate efficacy of sublingual misoprostol versus oxytocin drip for induction and augmentation of labor in prelabor rupture of membranes. METHODS: The study included 200 pregnant women with singleton term pregnancy with cephalic presentation, leaking per vaginum and no contraindications to vaginal delivery. They were randomised in two groups, 100 in sublingual misoprostol group and 100 for oxytocin drip group. Induction delivery interval, mode of delivery, incidence of operative interference and maternal and fetal outcome were noted and analysed. RESULTS: Mean induction delivery interval was $8 \mathrm{hrs}$ in misoprostol group and $15 \mathrm{hrs}$ in oxytocin group. Mode of delivery was vaginal in $99 \%$ in misoprostol group but $80 \%$ in oxytocin group. Sublingual misoprostol was associated with less meconium passage $(1 \%)$ compared to $20 \%$ in oxytocin group. CONCLUSION: Sublingual misoprostol is a good alternative to oxytocin drip for induction and augmentation of labour in women with PROM.

KEY WORDS: Sublingual Misoprostol, PROM

INTRODUCTION: Spontaneous rupture of membranes anytime beyond $28^{\text {th }}$ week of pregnancy but before the onset of labor is called Prelabour Rupture of Membranes (PROM). When membranes rupture beyond 37 weeks but before onset of labour, it is called Term PROM and when it occurs before 37 completed weeks it is called Preterm PROM. Rupture of membranes for more than 24 hours is called prolonged rupture of membranes. Incidence of PROM is approximately $8-10 \%$ of all pregnancies ${ }^{1,2}$.

Diagnosis of PROM can be made easily on the basis of history of sudden escape of watery amniotic fluid, sterile speculum examination, nitrazine test, fern test and amnisure 2 .

PROM is associated with various maternal complications like chorioamnionitis, placental abruption, PPH, endometritis and neonatal complications like early neonatal sepsis, pneumonia etc. At term, infection is the most serious complication associated with term PROM. Its risk increases from about $10 \%$ at onset to about $40 \%$ with ROM for 24 hours or more 2 . Other factors that need to be considered are the risks of cord prolapse, cord compression, or abruption with expectant management, as well as the cost and length of hospitalization while 
waiting for labor to begin. Hence there is a need for immediate induction and augmentation of labour in women with PROM.

Now there are more than one option for induction of labor in women with PROM. In this study we are comparing the efficacy of sublingual misoprostol with that of oxytocin infusion for induction of labour in women with PROM. Oxytocin is a potent uterine stimulant which has been conventionally been used for induction and augmentation of labor. But because it is a peptide, it carries the disadvantage of requiring only parenteral administration. Besides, it needs to be refrigerated at 2-8 C and has poor response in women with bishop score $<6$. Misoprostol on the other hand is a synthetic PGE1 analog which is less expensive, does not require parenteral administration, helps in cervical ripening in women with poor bishop score and can be stored at room temperature. This study aims to compare these two drugs for induction of labor in women with PROM.

METHODS: The present study was carried out on 200 women with singleton term pregnancies and cephalic presentation. All these women had no contraindication to vaginal delivery, had cervical dilatation $<3 \mathrm{~cm}$ and were admitted with history of leaking per vaginum. All those women with uterine scar (myomectomy/ hysterotomy), malpresentations, grandmultipatity, unexplained vaginal bleeding, fever and other medical disorders were excluded from the study.

They were randomly divided in two groups of 100 women each. Group I received 25 mcg sublingual misoprostol which was repeated every $4 \mathrm{hrs}$ if required to a maximum of 6 doses. Group II received 2 IU oxytocin in $500 \mathrm{ml}$ RL started at 1-2 mIU / min and escalated every 30 min till adequate uterine contractions were achieved. Partogram was maintained and active intervention was done at appearance of fetal distress, maternal distress or non- progress of labour.

The induction delivery interval, mode of delivery and incidence of operative interference were recorded. Maternal and perinatal outcome in both groups was noted and analysed.

RESULTS: This study included 200 women with 100 women in each oxytocin and sublingual misoprostol group. In the sublingual misoprostol group $22 \%$ women were $<20 y r s, 58 \%$ between 21-25 yrs and 20\% between 26-30 yrs. Similarly in oxytocin group 24\% women were $<20$ yrs, 51\% between 21-25yrs and 25\% between 26-30 yrs. Primi patients were $64 \%$ and $58 \%$ and multigravidas were $36 \%$ and $42 \%$ in misoprostol and oxytocin groups respectively. Thus the two groups were well matched in terms of age-wise distribution and parity.

Table no 1 shows the incidence of various complications and side effects. The incidence of uterine hyperstimulation, nausea- vomiting was more in sublingual misoprostol group (2\% vs $0 \%, 3 \%$ vs $0 \%$ ). But the incidence of cervical tears, fetal distress and fever was much more in oxytocin group ( $12 \%$ vs $1 \%, 20 \%$ vs $1 \%$ and $10 \%$ vs. $1 \%$ respectively). According to RCOG evidence based clinical guidelines also oral misoprostol results in fewer cases of hypercontractility without FHR changes. There is no difference in uterine hypercontractility with FHR changes 5 .

In sublingual misoprostol group out of 100 women, 99 (i.e. 99\%) delivered vaginally whereas in oxytocin group only $80 \%$ delivered vaginally and $20 \%$ underwent caesarean compared to only $1 \%$ in sublingual misoprostol group. The mean induction delivery interval was $8 \mathrm{hrs}$ in sublingual misoprostol group. This is significantly less than $15 \mathrm{hrs}$ in oxytocin group.

Table no 2 shows neonatal outcome in terms of APGAR score at 1 and $5 \mathrm{~min}$ in both the groups. 
DISCUSSION AND CONCLUSION: Evaluation of effective methods for induction and augmentation of labour in PROM has a very important role in obstetrics as timely and safe induction can reduce maternal and neonatal morbidity and mortality.

This study showed that contrary to popular belief incidence of complications and side effects was relatively less in sublingual misoprostol group compared to oxytocin group. Incidence of cervical tears, fetal distress and fever was $1 \%$ each in sublingual misoprostol group compared to $12 \%, 20 \%$ and $10 \%$ in oxytocin group. Only nausea- vomiting which is a drug related side effect and uterine hyperstimulation was slightly more in misoprostol group.

99\% women in sublingual misoprostol group delivered vaginally compared to only $80 \%$ in oxytocin group. The mean induction delivery interval in misoprostol group was almost half of that in oxytocin group ( $8 \mathrm{hrs}$ and $15 \mathrm{hrs}$ ). Women receiving oral misoprostol had more chances of delivering vaginally within 24 hours (RR 0.16 ; 95\% CI $0.05-0.49$ ), required less oxytocin (RR 0.35; 95\% CI 0.28-0.44) and had a lower caesarean section rate (RR 0.61; 95\% CI 0.41-0.93) . Another study conducted by A Nigam et al also found similar results. In their study, they found that Induction-delivery interval was shorter with misoprostol $(7.7 \pm 2.8 \mathrm{~h}$ against $14.3 \pm 4.8 \mathrm{~h}$ with oxytocin) but the rates of vaginal delivery, cesarean, neonatal outcome variables were similar. Hence, misoprostol is an effective agent for induction of labor at term 6 .

Three studies comparing buccal/sublingual misoprostol respectively with a vaginal regimen and with oral administration found that the buccal route was associated with fewer caesarean sections than with the vaginal route. There were no significant differences in any other outcomes. When the same dosage was used sublingually versus orally, the sublingual route was associated with less failure to achieve vaginal delivery within 24 hours, reduced oxytocin augmentation and reduced caesarean section; but the differences were not statistically significant ${ }^{4}$.

In another study conducted by Dr. Shital Julani conducted at BJMC, Pune similar results were reported. They also reported incidence of vaginal deliveries to be more in sublingual misoprostol group (96\%) compared to $84 \%$ in oxytocin group. Induction delivery interval was also $8.12 \mathrm{hrs}$ in sublingual misoprostol group compared to $9 \mathrm{hrs}$ in oxytocin group.

The present study revealed that misoprostol is a very effective agent for induction and augmentation of labour in PROM when used sublingually. Rather it seems to have better efficacy than oxytocin infusion since it decreases induction delivery interval with better success rates and fewer complications. Misoprostol is cheap, easily available, has no specific temperature or storage requirements and with no need for IV access. Most importantly it is effective even in patients with poor bishop's scores. Thus misoprostol is a good alternative to oxytocin infusion for induction and augmentation of labour in women with PROM.

\section{REFERENCES:}

1. Dare M.R., Middleton P, Crowther C.A., Flenady V.J., Varatharaju B.Planned early birth versus expectant management (waiting) for prelabour rupture of membranes at term (37 weeks or more).Cochrane Database of Systematic Reviews 2006, Issue 1. Art. No.: CD005302. DOI: 10.1002/14651858.CD005302.pub2. (level I) 05302/frame.html

2. eMedicine Specialties > Obstetrics and Gynecology > Obstetrical Complications. Premature Rupture of Membranes. Author: Allahyar Jazayeri, MD, PhD, FACOG, DACOG, FSMFM, Women Specialty Care, Green Bay WI; Medical Director of Perinatal Services, Bellin Health Hospital Center Contributor Information and Disclosures. Updated: May 7, 2010 
3. Abdel-Aleem H. Misoprostol for cervical ripening and induction of labour: RHL commentary (last revised: 1 August 2009). The WHO Reproductive Health Library; Geneva: World Health Organization.

4. Muzonzini G, Hofmeyr GJ. Buccal or sublingual misoprostol for cervical ripening and induction of labour. Cochrane Database of Systematic Reviews 2004, Issue 4. Art. No.: CD004221. DOI: 10.1002/14651858.CD004221.pub2

5. RCOG evidence based clinical guideline no9, june 2001.

6. A. Nigam, V.K. Singh, P. Dubay, K. Pandey, A. Bhagoliwal, A. Prakash, Misoprostol vs. oxytocin for induction of labor at term. International Journal of Gynecology \& Obstetrics

Volume 86, Issue 3 , (398-400), September 2004

Table 1: Incidence of complications and side effects

\begin{tabular}{|c|c|c|c|c|c|}
\hline S no. & $\begin{array}{l}\text { Complications and } \\
\text { Side Effects }\end{array}$ & $\begin{array}{l}\text { Sublingual } \\
\text { Misoprostol } \\
\text { Group }\end{array}$ & $\%$ & $\begin{array}{l}\text { Oxytocin } \\
\text { Group }\end{array}$ & $\%$ \\
\hline 1. & Fetal Distress & 1 & 1 & 20 & $\begin{array}{l}2 \\
0\end{array}$ \\
\hline 2. & $\begin{array}{l}\text { Uterine Hyperstimulation } \\
\text { Syndrome }\end{array}$ & 2 & 2 & 0 & 0 \\
\hline 3. & Cervical Tear & 1 & 1 & 12 & $\begin{array}{l}1 \\
2\end{array}$ \\
\hline 4. & Vaginal Laceration & 0 & 0 & 0 & 0 \\
\hline 5. & $1^{0}$ Perineal Tear & 0 & 0 & 1 & 1 \\
\hline 6. & Fever & 2 & 2 & 10 & $\begin{array}{l}1 \\
0\end{array}$ \\
\hline 7. & Nausea, Vomiting & 3 & 3 & 0 & 0 \\
\hline 8. & Postpartum Uterine Atony & 0 & 0 & 0 & 0 \\
\hline
\end{tabular}

Table 2: Neonatal Outcome in terms of APGAR score

\begin{tabular}{lllll}
\hline APGAR & \multicolumn{2}{l}{ Sublingual Misoprostol } & \multicolumn{2}{c}{ Oxytocin Infusion } \\
\hline & 1 min. & $5 \mathrm{~min}$. & $1 \mathrm{~min}$. & $5 \mathrm{~min}$. \\
$\mathbf{0}$ & 0 & 0 & 1 & 1 \\
$\mathbf{2}$ & 0 & 0 & 0 & 0 \\
$\mathbf{4}$ & 0 & 0 & 3 & 3 \\
$\mathbf{6}$ & 0 & 0 & 0 & 0 \\
$\mathbf{8}$ & 22 & 0 & 30 & 0 \\
$\mathbf{1 0}$ & 78 & 100 & 66 & 66 \\
\hline
\end{tabular}

